\title{
Ishikawa Iterative Process for a Pair of Single-valued and Multivalued Nonexpansive Mappings in Banach Spaces
}

\author{
K. Sokhuma ${ }^{1}$ and A. Kaewkhao ${ }^{2}$ \\ ${ }^{1}$ Department of Mathematics, Faculty of Science, Burapha University, Chonburi 20131, Thailand \\ ${ }^{2}$ Department of Mathematics, Faculty of Science, Chiang Mai University, Chiang Mai 50200, Thailand
}

Correspondence should be addressed to A. Kaewkhao, akaewkhao@yahoo.com

Received 8 August 2010; Accepted 24 September 2010

Academic Editor: T. D. Benavides

Copyright (C) 2010 K. Sokhuma and A. Kaewkhao. This is an open access article distributed under the Creative Commons Attribution License, which permits unrestricted use, distribution, and reproduction in any medium, provided the original work is properly cited.

Let $E$ be a nonempty compact convex subset of a uniformly convex Banach space $X$, and let $t: E \rightarrow E$ and $T: E \rightarrow K C(E)$ be a single-valued nonexpansive mapping and a multivalued nonexpansive mapping, respectively. Assume in addition that $\operatorname{Fix}(t) \cap \operatorname{Fix}(T) \neq \emptyset$ and $T w=\{w\}$ for all $w \in \operatorname{Fix}(t) \cap \operatorname{Fix}(T)$. We prove that the sequence of the modified Ishikawa iteration method generated from an arbitrary $x_{0} \in E$ by $y_{n}=\left(1-\beta_{n}\right) x_{n}+\beta_{n} z_{n}, x_{n+1}=\left(1-\alpha_{n}\right) x_{n}+\alpha_{n} t y_{n}$, where $z_{n} \in T x_{n}$ and $\left\{\alpha_{n}\right\},\left\{\beta_{n}\right\}$ are sequences of positive numbers satisfying $0<a \leq \alpha_{n}, \beta_{n} \leq b<1$, converges strongly to a common fixed point of $t$ and $T$; that is, there exists $x \in E$ such that $x=t x \in T x$.

\section{Introduction}

Let $X$ be a Banach space, and let $E$ be a nonempty subset of $X$. We will denote by $F B(E)$ the family of nonempty bounded closed subsets of $E$ and by $K C(E)$ the family of nonempty compact convex subsets of $E$. Let $H(\cdot, \cdot)$ be the Hausdorff distance on $F B(X)$, that is,

$$
H(A, B)=\max \left\{\sup _{a \in A} \operatorname{dist}(a, B), \sup _{b \in B} \operatorname{dist}(b, A)\right\}, \quad A, B \in F B(X),
$$

where $\operatorname{dist}(a, B)=\inf \{\|a-b\|: b \in B\}$ is the distance from the point $a$ to the subset $B$. 
A mapping $t: E \rightarrow E$ is said to be nonexpansive if

$$
\|t x-t y\| \leq\|x-y\|, \quad \forall x, y \in E .
$$

A point $x$ is called a fixed point of $t$ if $t x=x$.

A multivalued mapping $T: E \rightarrow F B(X)$ is said to be nonexpansive if

$$
H(T x, T y) \leq\|x-y\|, \quad \forall x, y \in E
$$

A point $x$ is called a fixed point for a multivalued mapping $T$ if $x \in T x$.

We use the notation $\operatorname{Fix}(T)$ standing for the set of fixed points of a mapping $T$ and $\operatorname{Fix}(t) \cap \operatorname{Fix}(T)$ standing for the set of common fixed points of $t$ and $T$. Precisely, a point $x$ is called a common fixed point of $t$ and $T$ if $x=t x \in T x$.

In 2006, S. Dhompongsa et al. [1] proved a common fixed point theorem for two nonexpansive commuting mappings.

Theorem 1.1 (see [1, Theorem 4.2]). Let E be a nonempty bounded closed convex subset of a uniformly Banach space $X$, and let $t: E \rightarrow E$, and $T: E \rightarrow K C(E)$ be a nonexpansive mapping and a multivalued nonexpansive mapping, respectively. Assume that $t$ and $T$ are commuting; that is, if for every $x, y \in E$ such that $x \in T y$ and $t y \in E$, there holds $t x \in T t y$. Then, $t$ and $T$ have a common fixed point.

In this paper, we introduce an iterative process in a new sense, called the modified Ishikawa iteration method with respect to a pair of single-valued and multivalued nonexpansive mappings. We also establish the strong convergence theorem of a sequence from such process in a nonempty compact convex subset of a uniformly convex Banach space.

\section{Preliminaries}

The important property of the uniformly convex Banach space we use is the following lemma proved by Schu [2] in 1991.

Lemma 2.1 (see [2]). Let $X$ be a uniformly convex Banach space, let $\left\{u_{n}\right\}$ be a sequence of real numbers such that $0<b \leq u_{n} \leq c<1$ for all $n \geq 1$, and let $\left\{x_{n}\right\}$ and $\left\{y_{n}\right\}$ be sequences of $X$ such that $\limsup _{n \rightarrow \infty}\left\|x_{n}\right\| \leq a, \limsup _{n \rightarrow \infty}\left\|y_{n}\right\| \leq a$, and $\lim _{n \rightarrow \infty}\left\|u_{n} x_{n}+\left(1-u_{n}\right) y_{n}\right\|=a$ for some $a \geq 0$. Then, $\lim _{n \rightarrow \infty}\left\|x_{n}-y_{n}\right\|=0$.

The following observation will be used in proving our results, and the proof is straightforward.

Lemma 2.2. Let $X$ be a Banach space, and let $E$ be a nonempty closed convex subset of $X$. Then,

$$
\operatorname{dist}(y, T y) \leq\|y-x\|+\operatorname{dist}(x, T x)+H(T x, T y),
$$

where $x, y \in E$ and $T$ is a multivalued nonexpansive mapping from $E$ into $F B(E)$. 
A fundamental principle which plays a key role in ergodic theory is the demiclosedness principle. A mapping $t$ defined on a subset $E$ of a Banach space $X$ is said to be demiclosed if any sequence $\left\{x_{n}\right\}$ in $E$ the following implication holds: $x_{n} \rightarrow x$ and $t x_{n} \rightarrow y$ implies $t x=y$.

Theorem 2.3 (see [3]). Let E be a nonempty closed convex subset of a uniformly convex Banach space $X$, and let $t: E \rightarrow E$ be a nonexpansive mapping. If a sequence $\left\{x_{n}\right\}$ in E converges weakly to $p$ and $\left\{x_{n}-t x_{n}\right\}$ converges to 0 as $n \rightarrow \infty$, then $p \in \operatorname{Fix}(t)$.

In 1974, Ishikawa introduced the following well-known iteration.

Definition 2.4 (see [4]). Let $X$ be a Banach space, let $E$ be a closed convex subset of $X$, and let $t$ be a selfmap on $E$. For $x_{0} \in E$, the sequence $\left\{x_{n}\right\}$ of Ishikawa iterates of $t$ is defined by

$$
\begin{gathered}
y_{n}=\left(1-\beta_{n}\right) x_{n}+\beta_{n} t x_{n}, \\
x_{n+1}=\left(1-\alpha_{n}\right) x_{n}+\alpha_{n} t y_{n}, \quad n \geq 0,
\end{gathered}
$$

where $\left\{\alpha_{n}\right\}$ and $\left\{\beta_{n}\right\}$ are real sequences.

A nonempty subset $K$ of $E$ is said to be proximinal if, for any $x \in E$, there exists an element $y \in K$ such that $\|x-y\|=\operatorname{dist}(x, K)$. We will denote $P(K)$ by the family of nonempty proximinal bounded subsets of $K$.

In 2005, Sastry and Babu [5] defined the Ishikawa iterative scheme for multivalued mappings as follows.

Let $E$ be a compact convex subset of a Hilbert space $X$, and let $T: E \rightarrow P(E)$ be a multivalued mapping, and fix $p \in \operatorname{Fix}(T)$.

$$
\begin{gathered}
x_{0} \in E, \\
y_{n}=\left(1-\beta_{n}\right) x_{n}+\beta_{n} z_{n}, \\
x_{n+1}=\left(1-\alpha_{n}\right) x_{n}+\alpha_{n} z_{n}^{\prime}, \quad \forall n \geq 0,
\end{gathered}
$$

where $\left\{\alpha_{n}\right\},\left\{\beta_{n}\right\}$ are sequences in $[0,1]$ with $z_{n} \in T x_{n}$ such that $\left\|z_{n}-p\right\|=\operatorname{dist}\left(p, T x_{n}\right)$ and $\left\|z_{n}^{\prime}-p\right\|=\operatorname{dist}\left(p, T y_{n}\right)$.

They also proved the strong convergence of the above Ishikawa iterative scheme for a multivalued nonexpansive mapping $T$ with a fixed point $p$ under some certain conditions in a Hilbert space.

Recently, Panyanak [6] extended the results of Sastry and Babu [5] to a uniformly convex Banach space and also modified the above Ishikawa iterative scheme as follows.

Let $E$ be a nonempty convex subset of a uniformly convex Banach space $X$, and let $T: E \rightarrow P(E)$ be a multivalued mapping

$$
\begin{gathered}
x_{0} \in E, \\
y_{n}=\left(1-\beta_{n}\right) x_{n}+\beta_{n} z_{n}, \\
x_{n+1}=\left(1-\alpha_{n}\right) x_{n}+\alpha_{n} z_{n}^{\prime}, \quad \forall n \geq 0,
\end{gathered}
$$


where $\left\{\alpha_{n}\right\},\left\{\beta_{n}\right\}$ are sequences in $[0,1]$ with $z_{n} \in T x_{n}$ and $u_{n} \in \operatorname{Fix}(T)$ such that $\| z_{n}-$ $u_{n} \|=\operatorname{dist}\left(u_{n}, T x_{n}\right)$ and $\left\|x_{n}-u_{n}\right\|=\operatorname{dist}\left(x_{n}, \operatorname{Fix}(T)\right)$, respectively. Moreover, $z_{n}^{\prime} \in T x_{n}$ and $v_{n} \in \operatorname{Fix}(T)$ such that $\left\|z_{n}^{\prime}-v_{n}\right\|=\operatorname{dist}\left(v_{n}, T x_{n}\right)$ and $\left\|y_{n}-v_{n}\right\|=\operatorname{dist}\left(y_{n}, \operatorname{Fix}(T)\right)$, respectively.

Very recently, Song and Wang $[7,8]$ improved the results of $[5,6]$ by means of the following Ishikawa iterative scheme.

Let $T: E \rightarrow F B(E)$ be a multivalued mapping, where $\alpha_{n}, \beta_{n} \in[0,1)$. The Ishikawa iterative scheme $\left\{x_{n}\right\}$ is defined by

$$
\begin{gathered}
x_{0} \in E, \\
y_{n}=\left(1-\beta_{n}\right) x_{n}+\beta_{n} z_{n}, \\
x_{n+1}=\left(1-\alpha_{n}\right) x_{n}+\alpha_{n} z_{n}^{\prime}, \quad \forall n \geq 0,
\end{gathered}
$$

where $z_{n} \in T x_{n}$ and $z_{n}^{\prime} \in T y_{n}$ such that $\left\|z_{n}-z_{n}^{\prime}\right\| \leq H\left(T x_{n}, T y_{n}\right)+\gamma_{n}$ and $\left\|z_{n+1}-z_{n}^{\prime}\right\| \leq$ $H\left(T x_{n+1}, T y_{n}\right)+\gamma_{n}$, respectively. Moreover, $\gamma_{n} \in(0,+\infty)$ such that $\lim _{n \rightarrow \infty} \gamma_{n}=0$.

At the same period, Shahzad and Zegeye [9] modified the Ishikawa iterative scheme $\left\{x_{n}\right\}$ and extended the result of [7, Theorem 2] to a multivalued quasinonexpansive mapping as follows.

Let $K$ be a nonempty convex subset of a Banach space $X$, and let $T: E \rightarrow F B(E)$ be a multivalued mapping, where $\alpha_{n}, \beta_{n} \in[0,1]$. The Ishikawa iterative scheme $\left\{x_{n}\right\}$ is defined by

$$
\begin{gathered}
x_{0} \in E, \\
y_{n}=\left(1-\beta_{n}\right) x_{n}+\beta_{n} z_{n}, \\
x_{n+1}=\left(1-\alpha_{n}\right) x_{n}+\alpha_{n} z_{n}^{\prime}, \quad \forall n \geq 0,
\end{gathered}
$$

where $z_{n} \in T x_{n}$ and $z_{n}^{\prime} \in T y_{n}$.

In this paper, we introduce a new iteration method modifying the above ones and call it the modified Ishikawa iteration method.

Definition 2.5. Let $E$ be a nonempty closed bounded convex subset of a Banach space $X$, let $t$ : $E \rightarrow E$ be a single-valued nonexpansive mapping, and let $T: E \rightarrow F B(E)$ be a multivalued nonexpansive mapping. The sequence $\left\{x_{n}\right\}$ of the modified Ishikawa iteration is defined by

$$
\begin{gathered}
y_{n}=\left(1-\beta_{n}\right) x_{n}+\beta_{n} z_{n}, \\
x_{n+1}=\left(1-\alpha_{n}\right) x_{n}+\alpha_{n} t y_{n},
\end{gathered}
$$

where $x_{0} \in E, z_{n} \in T x_{n}$, and $0<a \leq \alpha_{n}, \beta_{n} \leq b<1$.

\section{Main Results}

We first prove the following lemmas, which play very important roles in this section.

Lemma 3.1. Let $E$ be a nonempty compact convex subset of a uniformly convex Banach space $X$, and let $t: E \rightarrow E$ and $T: E \rightarrow F B(E)$ be a single-valued and a multivalued nonexpansive mapping, 
respectively, and $\operatorname{Fix}(t) \cap \operatorname{Fix}(T) \neq \emptyset$ satisfying $T w=\{w\}$ for all $w \in \operatorname{Fix}(t) \cap \operatorname{Fix}(T)$. Let $\left\{x_{n}\right\}$ be the sequence of the modified Ishikawa iteration defined by (2.7). Then, $\lim _{n \rightarrow \infty}\left\|x_{n}-w\right\|$ exists for all $w \in \operatorname{Fix}(t) \cap \operatorname{Fix}(T)$.

Proof. Letting $x_{0} \in E$ and $w \in \operatorname{Fix}(t) \cap \operatorname{Fix}(T)$, we have

$$
\begin{aligned}
\left\|x_{n+1}-w\right\| & =\left\|\left(1-\alpha_{n}\right) x_{n}+\alpha_{n} t\left(\left(1-\beta_{n}\right) x_{n}+\beta_{n} z_{n}\right)-w\right\| \\
& =\left\|\left(1-\alpha_{n}\right) x_{n}+\alpha_{n} t\left(\left(1-\beta_{n}\right) x_{n}+\beta_{n} z_{n}\right)-\left(1-\alpha_{n}\right) w-\alpha_{n} w\right\| \\
& \leq\left(1-\alpha_{n}\right)\left\|x_{n}-w\right\|+\alpha_{n}\left\|t\left(\left(1-\beta_{n}\right) x_{n}+\beta_{n} z_{n}\right)-w\right\| \\
& \leq\left(1-\alpha_{n}\right)\left\|x_{n}-w\right\|+\alpha_{n}\left\|\left(1-\beta_{n}\right) x_{n}+\beta_{n} z_{n}-w\right\| \\
& =\left(1-\alpha_{n}\right)\left\|x_{n}-w\right\|+\alpha_{n}\left\|\left(1-\beta_{n}\right) x_{n}+\beta_{n} z_{n}-\left(1-\beta_{n}\right) w-\beta_{n} w\right\| \\
& \leq\left(1-\alpha_{n}\right)\left\|x_{n}-w\right\|+\alpha_{n}\left(1-\beta_{n}\right)\left\|x_{n}-w\right\|+\alpha_{n} \beta_{n}\left\|z_{n}-w\right\| \\
& =\left(1-\alpha_{n}\right)\left\|x_{n}-w\right\|+\alpha_{n}\left(1-\beta_{n}\right)\left\|x_{n}-w\right\|+\alpha_{n} \beta_{n} \operatorname{dist}\left(z_{n}, T w\right) \\
& \leq\left(1-\alpha_{n}\right)\left\|x_{n}-w\right\|+\alpha_{n}\left(1-\beta_{n}\right)\left\|x_{n}-w\right\|+\alpha_{n} \beta_{n} H\left(T x_{n}, T w\right) \\
& \leq\left(1-\alpha_{n}\right)\left\|x_{n}-w\right\|+\alpha_{n}\left(1-\beta_{n}\right)\left\|x_{n}-w\right\|+\alpha_{n} \beta_{n}\left\|x_{n}-w\right\| \\
& =\left\|x_{n}-w\right\| .
\end{aligned}
$$

Since $\left\{\left\|x_{n}-w\right\|\right\}$ is a decreasing and bounded sequence, we can conclude that the limit of $\left\{\left\|x_{n}-w\right\|\right\}$ exists.

We can see how Lemma 2.1 is useful via the following lemma.

Lemma 3.2. Let $E$ be a nonempty compact convex subset of a uniformly convex Banach space $X$, and let $t: E \rightarrow E$ and $T: E \rightarrow F B(E)$ be a single-valued and a multivalued nonexpansive mapping, respectively, and $\operatorname{Fix}(t) \cap \operatorname{Fix}(T) \neq \emptyset$ satisfying $T w=\{w\}$ for all $w \in \operatorname{Fix}(t) \cap \operatorname{Fix}(T)$. Let $\left\{x_{n}\right\}$ be the sequence of the modified Ishikawa iteration defined by (2.7). If $0<a \leq \alpha_{n} \leq b<1$ for some $a, b \in \mathbb{R}$, then, $\lim _{n \rightarrow \infty}\left\|t y_{n}-x_{n}\right\|=0$.

Proof. Let $w \in \operatorname{Fix}(t) \cap \operatorname{Fix}(T)$. By Lemma 3.1, we put $\lim _{n \rightarrow \infty}\left\|x_{n}-w\right\|=c$ and consider

$$
\begin{aligned}
\left\|t y_{n}-w\right\| & \leq\left\|y_{n}-w\right\| \\
& =\left\|\left(1-\beta_{n}\right) x_{n}+\beta_{n} z_{n}-w\right\| \\
& \leq\left(1-\beta_{n}\right)\left\|x_{n}-w\right\|+\beta_{n}\left\|z_{n}-w\right\| \\
& =\left(1-\beta_{n}\right)\left\|x_{n}-w\right\|+\beta_{n} \operatorname{dist}\left(z_{n}, T w\right) \\
& \leq\left(1-\beta_{n}\right)\left\|x_{n}-w\right\|+\beta_{n} H\left(T x_{n}, T w\right) \\
& \leq\left(1-\beta_{n}\right)\left\|x_{n}-w\right\|+\beta_{n}\left\|x_{n}-w\right\| \\
& =\left\|x_{n}-w\right\| .
\end{aligned}
$$


Then, we have

$$
\limsup _{n \rightarrow \infty}\left\|t y_{n}-w\right\| \leq \limsup _{n \rightarrow \infty}\left\|y_{n}-w\right\| \leq \limsup _{n \rightarrow \infty}\left\|x_{n}-w\right\|=c
$$

Further, we have

$$
\begin{aligned}
c & =\lim _{n \rightarrow \infty}\left\|x_{n+1}-w\right\| \\
& =\lim _{n \rightarrow \infty}\left\|\left(1-\alpha_{n}\right) x_{n}+\alpha_{n} t y_{n}-w\right\| \\
& =\lim _{n \rightarrow \infty}\left\|\alpha_{n} t y_{n}-\alpha_{n} w+x_{n}-\alpha_{n} x_{n}+\alpha_{n} w-w\right\| \\
& =\lim _{n \rightarrow \infty}\left\|\alpha_{n}\left(t y_{n}-w\right)+\left(1-\alpha_{n}\right)\left(x_{n}-w\right)\right\| .
\end{aligned}
$$

By Lemma 2.1, we can conclude that $\lim _{n \rightarrow \infty}\left\|\left(t y_{n}-w\right)-\left(x_{n}-w\right)\right\|=\lim _{n \rightarrow \infty}\left\|t y_{n}-x_{n}\right\|=0$.

Lemma 3.3. Let E be a nonempty compact convex subset of a uniformly convex Banach space $X$, and let $t: E \rightarrow E$ and $T: E \rightarrow F B(E)$ be a single-valued and a multivalued nonexpansive mapping, respectively, and $\operatorname{Fix}(t) \cap \operatorname{Fix}(T) \neq \emptyset$ satisfying $T w=\{w\}$ for all $w \in \operatorname{Fix}(t) \cap \operatorname{Fix}(T)$. Let $\left\{x_{n}\right\}$ be the sequence of the modified Ishikawa iteration defined by (2.7). If $0<a \leq \alpha_{n}, \beta_{n} \leq b<1$ for some $a, b \in \mathbb{R}$, then $\lim _{n \rightarrow \infty}\left\|x_{n}-z_{n}\right\|=0$.

Proof. Let $w \in \operatorname{Fix}(t) \cap \operatorname{Fix}(T)$. We put, as in Lemma 3.2, $\lim _{n \rightarrow \infty}\left\|x_{n}-w\right\|=c$. For $n \geq 0$, we have

$$
\begin{aligned}
\left\|x_{n+1}-w\right\| & =\left\|\left(1-\alpha_{n}\right) x_{n}+\alpha_{n} t y_{n}-w\right\| \\
& =\left\|\left(1-\alpha_{n}\right) x_{n}+\alpha_{n} t y_{n}-\left(1-\alpha_{n}\right) w-\alpha_{n} w\right\| \\
& \leq\left(1-\alpha_{n}\right)\left\|x_{n}-w\right\|+\alpha_{n}\left\|t y_{n}-w\right\| \\
& \leq\left(1-\alpha_{n}\right)\left\|x_{n}-w\right\|+\alpha_{n}\left\|y_{n}-w\right\|
\end{aligned}
$$

and hence

$$
\begin{aligned}
& \left\|x_{n+1}-w\right\|-\left\|x_{n}-w\right\| \leq-\alpha_{n}\left\|x_{n}-w\right\|+\alpha_{n}\left\|y_{n}-w\right\|, \\
& \left\|x_{n+1}-w\right\|-\left\|x_{n}-w\right\| \leq \alpha_{n}\left(\left\|y_{n}-w\right\|-\left\|x_{n}-w\right\|\right), \\
& \frac{\left\|x_{n+1}-w\right\|-\left\|x_{n}-w\right\|}{\alpha_{n}} \leq\left\|y_{n}-w\right\|-\left\|x_{n}-w\right\| .
\end{aligned}
$$

Therefore, since $0<a \leq \alpha_{n} \leq b<1$,

$$
\left(\frac{\left\|x_{n+1}-w\right\|-\left\|x_{n}-w\right\|}{\alpha_{n}}\right)+\left\|x_{n}-w\right\| \leq\left\|y_{n}-w\right\|
$$


Thus,

$$
\liminf _{n \rightarrow \infty}\left\{\left(\frac{\left\|x_{n+1}-w\right\|-\left\|x_{n}-w\right\|}{\alpha_{n}}\right)+\left\|x_{n}-w\right\|\right\} \leq \liminf _{n \rightarrow \infty}\left\|y_{n}-w\right\|
$$

It follows that

$$
c \leq \liminf _{n \rightarrow \infty}\left\|y_{n}-w\right\|
$$

Since, from (3.3), $\limsup _{n \rightarrow \infty}\left\|y_{n}-w\right\| \leq c$, we have

$$
\begin{aligned}
c & =\lim _{n \rightarrow \infty}\left\|y_{n}-w\right\| \\
& =\lim _{n \rightarrow \infty}\left\|\left(1-\beta_{n}\right) x_{n}+\beta_{n} z_{n}-w\right\| \\
& =\lim _{n \rightarrow \infty}\left\|\left(1-\beta_{n}\right)\left(x_{n}-w\right)+\beta_{n}\left(z_{n}-w\right)\right\| .
\end{aligned}
$$

Recall that

$$
\begin{aligned}
\left\|z_{n}-w\right\| & =\operatorname{dist}\left(z_{n}, T w\right) \\
& \leq H\left(T x_{n}, T w\right) \\
& \leq\left\|x_{n}-w\right\| .
\end{aligned}
$$

Hence, we have

$$
\limsup _{n \rightarrow \infty}\left\|z_{n}-w\right\| \leq \limsup _{n \rightarrow \infty}\left\|x_{n}-w\right\|=c
$$

Using the fact that $0<a \leq \beta_{n} \leq b<1$ and by (3.10), we can conclude that $\lim _{n \rightarrow \infty}\left\|x_{n}-z_{n}\right\|=$ 0 .

The following lemma allows us to go on.

Lemma 3.4. Let $E$ be a nonempty compact convex subset of a uniformly convex Banach space $X$, and let $t: E \rightarrow E$ and $T: E \rightarrow F B(E)$ be a single-valued and a multivalued nonexpansive mapping, respectively, and $\operatorname{Fix}(t) \cap \operatorname{Fix}(T) \neq \emptyset$ satisfying $T w=\{w\}$ for all $w \in \operatorname{Fix}(t) \cap \operatorname{Fix}(T)$. Let $\left\{x_{n}\right\}$ be the sequence of the modified Ishikawa iteration defined by (2.7). If $0<a \leq \alpha_{n}, \beta_{n} \leq b<1$, then $\lim _{n \rightarrow \infty}\left\|t x_{n}-x_{n}\right\|=0$. 
Proof. Consider

$$
\begin{aligned}
\left\|t x_{n}-x_{n}\right\| & =\left\|t x_{n}-t y_{n}+t y_{n}-x_{n}\right\| \\
& \leq\left\|t x_{n}-t y_{n}\right\|+\left\|t y_{n}-x_{n}\right\| \\
& \leq\left\|x_{n}-y_{n}\right\|+\left\|t y_{n}-x_{n}\right\| \\
& =\left\|x_{n}-\left(1-\beta_{n}\right) x_{n}-\beta_{n} z_{n}\right\|+\left\|t y_{n}-x_{n}\right\| \\
& =\left\|x_{n}-x_{n}+\beta_{n} x_{n}-\beta_{n} z_{n}\right\|+\left\|t y_{n}-x_{n}\right\| \\
& =\beta_{n}\left\|x_{n}-z_{n}\right\|+\left\|t y_{n}-x_{n}\right\| .
\end{aligned}
$$

Then, we have

$$
\lim _{n \rightarrow \infty}\left\|t x_{n}-x_{n}\right\| \leq \lim _{n \rightarrow \infty} \beta_{n}\left\|x_{n}-z_{n}\right\|+\lim _{n \rightarrow \infty}\left\|t y_{n}-x_{n}\right\|
$$

Hence, by Lemmas 3.2 and 3.3, $\lim _{n \rightarrow \infty}\left\|t x_{n}-x_{n}\right\|=0$.

We give the sufficient conditions which imply the existence of common fixed points for single-valued mappings and multivalued nonexpansive mappings, respectively, as follows

Theorem 3.5. Let E be a nonempty compact convex subset of a uniformly convex Banach space X, and let $t: E \rightarrow E$ and $T: E \rightarrow F B(E)$ be a single-valued and a multivalued nonexpansive mapping, respectively, and $\operatorname{Fix}(t) \cap \operatorname{Fix}(T) \neq \emptyset$ satisfying $T w=\{w\}$ for all $w \in \operatorname{Fix}(t) \cap \operatorname{Fix}(T)$. Let $\left\{x_{n}\right\}$ be the sequence of the modified Ishikawa iteration defined by (2.7). If $0<a \leq \alpha_{n}, \beta_{n} \leq b<1$, then $x_{n_{i}} \rightarrow y$ for some subsequence $\left\{x_{n_{i}}\right\}$ of $\left\{x_{n}\right\}$ implies $y \in \operatorname{Fix}(t) \cap \operatorname{Fix}(T)$.

Proof. Assume that $\lim _{n \rightarrow \infty}\left\|x_{n_{i}}-y\right\|=0$. From Lemma 3.4, we have

$$
0=\lim _{n \rightarrow \infty}\left\|t x_{n_{i}}-x_{n_{i}}\right\|=\lim _{n \rightarrow \infty}\left\|(I-t)\left(x_{n_{i}}\right)\right\|
$$

Since $I-t$ is demiclosed at 0 , we have $(I-t)(y)=0$, and hence $y=t y$, that is, $y \in \operatorname{Fix}(t)$. By Lemma 2.2 and by Lemma 3.4, we have

$$
\begin{aligned}
\operatorname{dist}(y, T y) & \leq\left\|y-x_{n_{i}}\right\|+\operatorname{dist}\left(x_{n_{i}}, T x_{n_{i}}\right)+H\left(T x_{n_{i}}, T y\right) \\
& \leq\left\|y-x_{n_{i}}\right\|+\left\|x_{n_{i}}-z_{n_{i}}\right\|+\left\|x_{n_{i}}-y\right\| \longrightarrow 0, \quad \text { as } i \rightarrow \infty .
\end{aligned}
$$

It follows that $y \in \operatorname{Fix}(T)$. Therefore $y \in \operatorname{Fix}(t) \cap \operatorname{Fix}(T)$ as desired.

Hereafter, we arrive at the convergence theorem of the sequence of the modified Ishikawa iteration. We conclude this paper with the following theorem.

Theorem 3.6. Let E be a nonempty compact convex subset of a uniformly convex Banach space X, and let $t: E \rightarrow E$ and $T: E \rightarrow F B(E)$ be a single-valued and a multivalued nonexpansive mapping, respectively, and $\operatorname{Fix}(t) \cap \operatorname{Fix}(T) \neq \emptyset$ satisfying $T w=\{w\}$ for all $w \in \operatorname{Fix}(t) \cap \operatorname{Fix}(T)$. Let $\left\{x_{n}\right\}$ be 
the sequence of the modified Ishikawa iteration defined by (2.7) with $0<a \leq \alpha_{n}, \beta_{n} \leq b<1$. Then $\left\{x_{n}\right\}$ converges strongly to a common fixed point of $t$ and $T$.

Proof. Since $\left\{x_{n}\right\}$ is contained in $E$ which is compact, there exists a subsequence $\left\{x_{n_{i}}\right\}$ of $\left\{x_{n}\right\}$ such that $\left\{x_{n_{i}}\right\}$ converges strongly to some point $y \in E$, that is, $\lim _{i \rightarrow \infty}\left\|x_{n_{i}}-y\right\|=0$. By Theorem 3.5, we have $y \in \operatorname{Fix}(t) \cap \operatorname{Fix}(T)$, and by Lemma 3.1, we have that $\lim _{n \rightarrow \infty}\left\|x_{n}-y\right\|$ exists. It must be the case in which $\lim _{n \rightarrow \infty}\left\|x_{n}-y\right\|=\lim _{i \rightarrow \infty}\left\|x_{n_{i}}-y\right\|=0$. Therefore, $\left\{x_{n}\right\}$ converges strongly to a common fixed point $y$ of $t$ and $T$.

\section{Acknowledgments}

The first author would like to thank the Office of the Higher Education Commission, Thailand for supporting by grant fund under the program Strategic Scholarships for Frontier Research Network for the Ph.D. Program Thai Doctoral degree for this research. The authors would like to express their deep gratitude to Prof. Dr. Sompong Dhompongsa whose guidance and support were valuable for the completion of the paper. This work was completed with the support of the Commission on Higher Education and The Thailand Research Fund under Grant no. MRG5180213.

\section{References}

[1] S. Dhompongsa, A. Kaewcharoen, and A. Kaewkhao, "The Domínguez-Lorenzo condition and multivalued nonexpansive mappings," Nonlinear Analysis: Theory, Methods \& Applications, vol. 64, no. 5, pp. 958-970, 2006.

[2] J. Schu, "Weak and strong convergence to fixed points of asymptotically nonexpansive mappings," Bulletin of the Australian Mathematical Society, vol. 43, no. 1, pp. 153-159, 1991.

[3] F. E. Browder, "Semicontractive and semiaccretive nonlinear mappings in Banach spaces," Bulletin of the American Mathematical Society, vol. 74, pp. 660-665, 1968.

[4] S. Ishikawa, "Fixed points by a new iteration method," Proceedings of the American Mathematical Society, vol. 44, pp. 147-150, 1974.

[5] K. P. R. Sastry and G. V. R. Babu, "Convergence of Ishikawa iterates for a multi-valued mapping with a fixed point," Czechoslovak Mathematical Journal, vol. 55(130), no. 4, pp. 817-826, 2005.

[6] B. Panyanak, "Mann and Ishikawa iterative processes for multivalued mappings in Banach spaces," Computers $\mathcal{E}$ Mathematics with Applications, vol. 54, no. 6, pp. 872-877, 2007.

[7] Y. Song and H. Wang, "Erratum to: "Mann and Ishikawa iterative processes for multivalued mappings in Banach spaces" [Comput. Math. Appl. 54 (2007) 872-877]," Computers \& Mathematics with Applications, vol. 55, no. 12, pp. 2999-3002, 2008.

[8] Y. Song and H. Wang, "Convergence of iterative algorithms for multivalued mappings in Banach spaces," Nonlinear Analysis: Theory, Methods E Applications, vol. 70, no. 4, pp. 1547-1556, 2009.

[9] N. Shahzad and H. Zegeye, "On Mann and Ishikawa iteration schemes for multi-valued maps in Banach spaces," Nonlinear Analysis: Theory, Methods \& Applications, vol. 71, no. 3-4, pp. 838-844, 2009. 